\title{
Description du mâle d'Osmia (Helicosmia) nasoproducta FERTON 1909 (Apoidea - Megachilidae - Osmiini)
}

\author{
par Gérard LE GOFF*
}

Résumé. Première description du mâle d'Osmia (Helicosmia) nasoproducta FERTON, collecté au Portugal (Algarve) au printemps 2014 à Zavial $\left(37,0461^{\circ} \mathrm{N}-8,8801^{\circ} \mathrm{O}\right)$.

Abstract. First description of the male Osmia (Helicosmia) nasoproducta FERTON, collected in Portugal (Algarve) during spring 2014 at Zavial $\left(37,0461^{\circ} \mathrm{N}-8,8801^{\circ} \mathrm{W}\right)$.

Mots-clés : mâle Osmia nasoproducta FERTON ; Osmiini ; première description.

Key-words : first description ; male Osmia nasoproducta FERTON ; Osmiini.

\section{Introduction}

Osmia nasoproducta est une abeille méditerranéenne peu fréquente qui butine préférentiellement les différentes espèces de Cistus, ainsi que des Cichorioideae et Carduoideae (Asteraceae) (MÜLLER, 2009). C'est au cours d'un séjour au Portugal, en avril 2014, que j'ai capturé un mâle à Zavial, dans la zone côtière. Il butinait du Cistus ladanifer L., très fréquent dans cette région, sans doute parce que les Cistus sont pyrophytes et qu'ils couvrent ainsi de grandes étendues en Algarve, suite aux incendies. Jusqu'à présent, le mâle d'Osmia nasoproducta n'a jamais été décrit, bien qu'il ait été photographié en 2012 par Yvo Raemakers dans le Roussillon.

\section{Description du mâle d'Osmia nasoproducta}

Matériel : mâle ( $\mathrm{N}^{\circ} 15311$ - collection G. Le Goff) 18-IV-2014 - Zavial - 37,0461ํN - 8,8801 ${ }^{\circ} \mathrm{O}$ (Algarve) Portugal

L'aspect général et la taille $(13 \mathrm{~mm})$ font penser au mâle d'Osmia dimidiata. C'est à l'examen qu'on note des caractères bien distincts. Le tégument est semblable à celui de la femelle, de couleur bronze. La pilosité générale est jaune roussâtre (la brosse de la femelle étant rousse) (figure 1).

\footnotetext{
* Gérard LE GoFf
}

44, rue Albert Malet, 76360 Barentin (F)

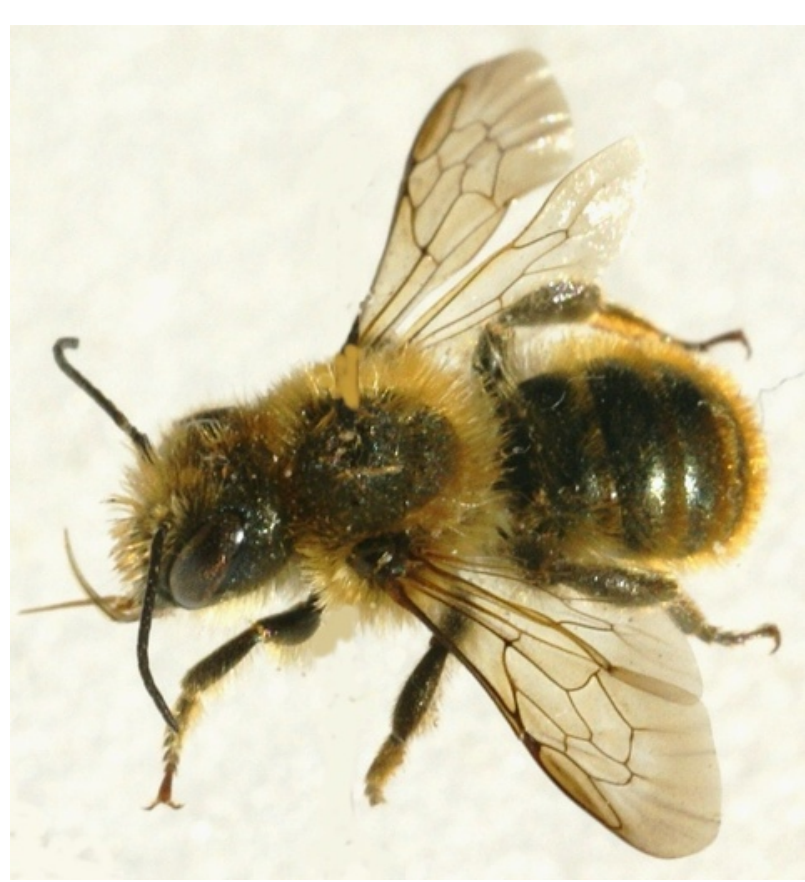

Figure 1. Mâle d'Osmia nasoproducta - Avril 2014 - Portugal. Photo : Gérard Le Goff

Tête : mandibules bidentées, brillantes et fortement sculptées : forte dent antérieure, la $2^{\text {ème }}$ est large et présente d'abord un aplat légèrement déclive vers l'arrière, suivi de la partie pointue vers l'arrière. Elles recouvrent le labre. Le clypeus, couvert de poils jaune roux, a une assez forte ponctuation serrée. Il est lisse et brillant à son bord antérieur. Celui-ci est 
bourrelé et présente des aspérités en forme de dents arrondies. Double pinceau de poils roussâtres à l'apex, suivis d'une courte suite de poils de même couleur de chaque côté. L'antenne est entièrement noire ; on note que le $2^{\text {ème }}$ article flagellaire est aussi long que le suivant (plus court chez dimidiata) (figure 2a). Le dernier article est aplati mais non spatulé. Les zones antennaire et occipitale sont fortement ponctuée. Forte pilosité jusqu'au milieu des antennes, plus courte et éparse vers les ocelles.

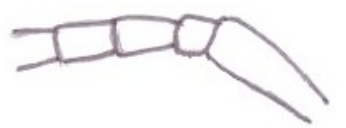

Figure 2a. Les premiers articles antennaires. Dessin : Gérard Le Goff

Thorax : avec une ponctuation serrée beaucoup plus fine que sur la tête lui donnant un aspect mat. Longue pilosité roussâtre. Zone subcordiforme presque verticale, mate, avec un rang de plis longitudinaux à la base. Tegulae brunes. La nervation est rousse à brune, seule la cellule radiale est fumée de roux dans sa moitié antérieure (la femelle a toutes les cellules teintées).

Abdomen : T1 à T4 à ponctuation fine et espacée (avec de très petits points épars entre les plus gros), plus serrée vers la marge apicale. Pilosité roussâtre sur T1 à T4, plus épaisse sur les côtés ; présence de franges apicales lâches de même couleur. T5 à ponctuation serrée. T6 avec des angles arrondis sur les côtés et les bords obtus à peine crénelés ; l'apex est échancré en arrondi. T7 présente aussi une échancrure, prolongée par 2 courtes dents pointues (figure $2 \mathrm{~b}$ ). Les derniers tergites ont une pilosité d'un roux plus vif, comme chez aurulenta.

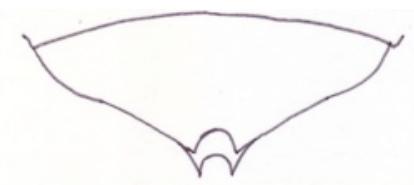

Figure 2b. Deux derniers tergites. Dessin : Gérard Le Goff

Sternites (figure 2c) : S2 très grand, avec une caractéristique spécifique : une échancrure centrale à l'apex. S3 présente une profonde échancrure arrondie bordée de longs poils roux ciliés tournés vers l'intérieur. S4 a le bord courbe, un peu linéaire à l'apex avec une courte pilosité.

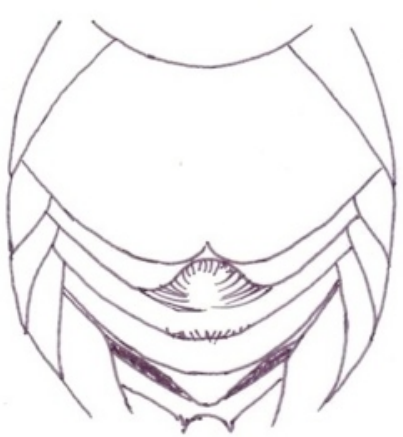

Figure 2c. Sternites. Dessin : Gérard Le Goff

Genitalia (figure 2d) : elles ressemblent beaucoup à celles des autres Osmies du sousgenre Helicosmia.

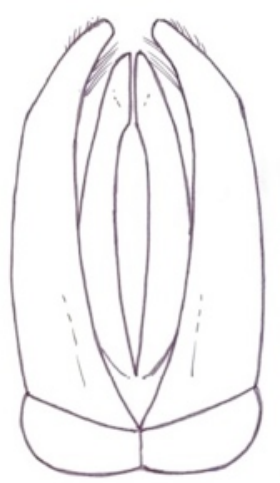

Figure 2d. Genitalia. Dessin : Gérard Le Goff

\section{Références bibliographiques}

Ferton C, 1909. Notes détachées sur l'instinct des hyménoptères mellifères et ravisseurs (5e Série) avec la description d'une espèce nouvelle. Annales de la Société Entomologique de France. Müller A, 2013. Palaearctic Osmiine Bees, ETH Zurich, http://blogs.ethz.ch/osmiini

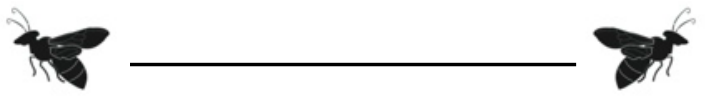

